\title{
TRATAMIENTO SUSTANTIVO DE LAS COSTAS EN LA JURISPRUDENCIA DE LA CORTE INTERAMERICANA DE DERECHOS HUMANOS*
}

\author{
SUSTANTIVE ANALYSIS OF COSTS IN \\ THE CASE LAW OF INTER-AMERICAN \\ COURT OF HUMAN RIGHTS
}

\author{
Jorge LeIVA-PovedA** \\ Fecha de recepción: 6 de mayo de 2016 \\ Fecha de aceptación: 1 de junio de 2016 \\ Disponible en linea: 30 de julio de 2016
}

\begin{abstract}
PARA CITAR eSTE ARtículo / To CITE THIS ARTICle
Leiva-Poveda, Jorge, Tratamiento sustantivo de las costas en la jurisprudencia de la Corte Interamericana de Derechos Humanos, 28 International Law, Revista Colombiana de Derecho Internacional, 209-246 (2016). http:// dx.doi. org/10.11144/Javeriana.il14-28.tscj

doi:10.11144/Javeriana.i114-28.tscj
\end{abstract}

* Este trabajo es producto de una investigación académica independiente y constituye un análisis documental auspiciado exclusivamente por el autor.

** Doctor en derecho administrativo, Universidad Escuela Libre de Derecho, San José de Costa Rica. Máster en protección de derechos humanos, especialista en derecho internacional y comunitario, ambos grados por la Universidad de Alcalá de Henares. Especialista en primer grado en derecho administrativo, Universidad de Salamanca. Actualmente, se desempeña como juez superior del Tribunal Superior Contencioso Administrativo de San José, es miembro de la Subcomisión de Acceso a la Justicia de los Pueblos Indígenas del Poder Judicial e integrante de la Comisión de Derecho Administrativo del Colegio de Abogados de Costa Rica. Contacto: jorgeelp@abogados.or.cr 


\section{RESUMEN}

El presente trabajo es la primera parte de un minucioso y exhaustivo análisis de los diversos criterios en materia de costas desarrollados por la Corte Interamericana de Derechos Humanos, concretamente respecto de las consideraciones sustantivas sobre este tema, verbigracia: fundamento normativo, procedencia según tipos de representación, criterios para la cuantificación y exoneración de este extremo en las sentencias condenatorias de ese Tribunal.

El objetivo de este estudio es ofrecer a investigadores universitarios y a potenciales litigantes en el Sistema Interamericano, una sistematización de los criterios utilizados por el Tribunal Continental, que permita conocer el tratamiento práctico de este instituto, más allá de las consideraciones genéricas y puramente teóricas frecuentemente expuestas en distintos foros. Como se verá a continuación, este documento muestra que la falta de regulación normativa de las costas ha impactado negativamente la seguridad jurídica del sistema, dados los diversos abordajes que la Corte Interamericana ha establecido en sus resoluciones en lo que hace a este tema.

Palabras clave: Corte Interamericana de Derechos Humanos; costas; jurisprudencia 


\section{ABSTRACT}

This paper is the first part of a detailed and in-depth analysis of the various criteria on costs developed by the Inter-American Court of Human Rights, specifically with regard to the substantive consideration of this issue, for instance: normative basis, origin according to type of representation, criteria for quantifying and exoneration of this in the sentences of the Tribunal. The aim of this paper is to provide university researchers and potential litigants in the Inter-American System with the criteria used by the Continental Court, which show the practical treatment of the institute beyond generic and purely theoretical considerations frequently exposed in different forums. As will be seen below, this paper shows that the lack of legislation regulating the issue of costs, has adversely impacted the legal security of the system, given the different approaches that the Court has established in its resolutions in regard to this topic.

Keywords: Inter-American Court of Human Rights; costs; case law

\section{SUMARIO}

Introducción. I. Fundamento JuRídico.- II. Definición JuRisPrudencial DEl instituto de las Costas.- III. El tratamiento de las Costas En El SisTEMA INTERAMERICANO ES INDEPENDIENTE DE LAS REGULACIONES INTERNAS DEL Estado demandado en ESA MATERIA.- IV. Costas y SUjetos Procesales.- V. Procedencia de las costas Según el tipo de representación. A. Representación a cargo de la Comisión Interamericana.- B. Representación a cargo de funcionarios públicos nacionales.- C. Representación a cargo de abogados litigantes u ONG.- VI. Criterios para la cuantificación de los honorarios profesionales que hacen parte de las costas.- VII. CONTRATOS DE CUOTALITIS.VIII. Exoneración del pago de costas al Estado demandado.- $A$. Consideraciones respecto de la exoneración total.- $B$. Consideraciones respecto de la exoneración parcial.- $C$. Consideraciones respecto de la exoneración en razón de la representación pro bono.- IX. GASTOS NO CUBIERTOS POR LAS COSTAS.- X. EXONERACIÓN TRIBUTARIA RESPECTO DE LAS COSTAS OTORGADAS EN el Sistema Interamericano.- Conclusiones.- Bibliografía. 
INTRODUCCIÓN

Desde la entrada en funcionamiento de la Corte Interamericana de Derechos Humanos, que se instaló el 3 de septiembre de 1979, en San José de Costa Rica, el tema de las costas ha sido uno de los ejes de discusión más frecuente. No obstante la Convención Americana sobre Derechos Humanos (también conocida como Pacto de San José) $)^{1}$ no hace mención de estas, en los siete reglamentos ${ }^{2}$ que han regido la actividad del Tribunal continental síse ha hecho mención de ellas ${ }^{3}$, sin ofrecer ningún tipo de precisión conceptual sobre el tema.

En los precedentes de la Corte Interamericana de Derechos Humanos se ha intentado precisar los aspectos procesales y sustantivos de este instituto. En los apartados siguientes, se sistematizarán y expondrán las consideraciones hechas por el Tribunal en esta materia, mismas que no necesariamente son compartidas en su totalidad por el autor, pero que en razón de la naturaleza académica del presente artículo deben ser expuestas. Aquí no está de más insistir en que las consideraciones que de seguido se ofrecerán no buscan hacer un desarrollo doctrinal respecto del instituto de las costas en procesos supranacionales, sino que simplemente se procura repasar de forma ordenada los criterios jurisprudenciales del Tribunal en lo que hace a este tema en particular.

Finalmente, se aclara que el análisis respecto del tratamiento procedimental de las costas en el proceso ante la Corte Interamericana de Derechos Humanos será objeto de un estudio posterior.

1 Organización de Estados Americanos, OEA, Convención Americana sobre Derechos Humanos, Pacto de San José, San José, Costa Rica, 7 al 22 de noviembre de 1969. Disponible en: https:// www.oas.org/dil/esp/tratados_B-32_Convencion_Americana_sobre_Derechos_Humanos.htm

2 Reglamento de la Corte Interamericana de Derechos Humanos, aprobado por la Corte en su XLIX Período Ordinario de Sesiones, celebrado del 16 al 25 de noviembre de 2001 y reformado parcialmente por la Corte en su LXXXII Período Ordinario de Sesiones, celebrado del 19 al 31 de enero de 2009. Disponible en: https://www.cidh.oas.org/basicos/Basicos12.htm. Reglamentos anteriores disponibles en: http://www.corteidh.or.cr/index.php/es/acerca-de/reglamento/ reglamentos-anteriores

3 Artículos 17, 34, 56, 59 del vigente Reglamento de la Corte Interamericana de Derechos $\mathrm{Hu}-$ manos, 31 de enero de 2009. Disponible en: https://www.cidh.oas.org/basicos/Basicos12.htm 


\section{FUNDAMENTO JURÍDICO}

Como se indicó en el apartado anterior, en las convenciones que reglamentan la actividad de la Corte Interamericana, a la fecha no se han incorporado regulaciones expresas en materia de costas. No obstante ello, ese Tribunal continental ha estimado jurisprudencialmente que las costas sí tienen sustento convencional, pues considera que están cubiertas por la normativa que regula de forma genérica el tema de las reparaciones en el Pacto de San José. En esa dirección, esa instancia judicial ha precisado: "133. Como ya lo ha señalado la Corte en oportunidades anteriores, las costas y gastos están comprendidos dentro del concepto de reparación establecido en el artículo 63.1 de la Convención Americana"4.

La norma convencional bajo análisis establece: "63.1. Cuando decida que hubo violación de un derecho o libertad protegidos en esta Convención, la Corte dispondrá que se garantice al lesionado en el goce de su derecho o libertad conculcados. Dispondrá asimismo, si ello fuera procedente, que se reparen las consecuencias de la medida o situación que ha configurado la vulneración de esos derechos y el pago de una justa indemnización a la parte lesionada".

Amén de lo expuesto, las únicas referencias al tema de costas en el Derecho Secundario del Sistema Interamericano se ubican en los reglamentos ${ }^{5}$. En esos textos si bien la Corte ha reconocido la existencia de costas, en ninguno de los siete Reglamentos que han regido su proceso ha definido su naturaleza y menos aún el alcance de su contenido.

4 Corte Interamericana de Derechos Humanos, Corte IDH, Caso Abrill-Alosilla y otros vs. Perú, Sentencia de 4 de marzo de 2011, Fondo, reparaciones y costas, Serie C 223, párrafo 133. Disponible en: http://www.corteidh.or.cr/docs/casos/articulos/seriec_223_esp.pdf

5 En este sentido, ver artículos 40, 41, 42, 65, y 66 del Reglamento de la Corte Interamericana de Derechos Humanos, aprobado por la Corte en su XLIX Período Ordinario de Sesiones, celebrado del 16 al 25 de noviembre de 2001 y reformado parcialmente por la Corte en su LXXXII Período Ordinario de Sesiones, celebrado del 19 al 31 de enero de 2009. Disponible en: https://www.cidh.oas.org/basicos/Basicos12.htm 


\section{DEFINICIÓN JURISPRUDENCIAL DEL} INSTITUTO DE LAS COSTAS

Según se refirió supra, ha sido vía jurisprudencia pretoriana que la Corte ha precisado qué rubros integran las costas que se pueden reclamar en razón de los procesos tramitados ante esa instancia. Conceptualizando este instituto, el referido Tribunal supranacional ha indicado: "150. Como lo ha señalado la Corte, las costas y gastos hacen parte del concepto de reparación, toda vez que la actividad desplegada por las víctimas con el fin de obtener justicia, implica erogaciones que deben ser compensadas cuando la responsabilidad internacional del Estado es declarada mediante una sentencia condenatoria".

En este punto, resulta necesario precisar que si bien la Corte ha insistido que las costas son parte de la reparación, este concepto en el proceso internacional no se agota ni es sinónimo de la indemnización. Respecto de esta precisión se ha indicado:

109. En cuanto a los gastos hechos como consecuencia de 16 años de litigio nacional e internacional y de la "difusión" del asunto, esta Corte hace notar que en algunos casos ha dispuesto el pago de indemnización por los gastos en los que las víctimas o sus familiares han incurrido como consecuencia de las violaciones declaradas, siempre que tengan un nexo causal directo con los hechos violatorios y no se trate de erogaciones realizadas con motivo del acceso a la justicia, ya que estas se consideran "reintegro de costas y gastos" y no "indemnizaciones". En el presente caso, los gastos mencionados derivan del acceso a la justicia, por lo que serán analizados en el apartado D) de este capitulo7.

En la misma dirección, el Tribunal continental ha señalado:

193. Esta Corte ha considerado en algunos casos que es procedente otorgar una indemnización por los gastos en los que las víctimas o sus familiares

6 Corte Interamericana de Derechos Humanos, Corte IDH, Caso Fleury y otros vs. Haití, Sentencia de 23 de noviembre de 2011, Fondo y reparaciones, Serie C 236, párrafo 150. Disponible en: http://corteidh.or.cr/docs/casos/articulos/seriec_236_esp.pdf

7 Corte Interamericana de Derechos Humanos, Corte IDH, Caso Kimel vs. Argentina, Sentencia de 2 de mayo de 2008, Fondo, reparaciones y costas, Serie C 177, párrafo 109. Disponible en: http://www.corteidh.or.cr/docs/casos/articulos/seriec_177_esp.pdf 
han incurrido como consecuencia de las violaciones declaradas, siempre que tales gastos tengan un nexo causal directo con los hechos violatorios y no se trate de erogaciones realizadas por motivo del acceso a la justicia, ya que estas últimas se consideran como "reintegro de costas y gastos" y no como "indemnizaciones".

Es simple, las costas y las indemnizaciones por daños son conceptos distintos que forman parte de las reparaciones que otorga esa instancia supraestatal.

No obstante la aparente coherencia de la consideración hecha por la Corte, la distinción bajo estudio no es plenamente pacífica en la jurisprudencia del Tribunal pues es posible encontrar excepcionalmente algunos precedentes en sentido contrario. Así, esa instancia también ha indicado lo siguiente:

316. (...) Los representantes solicitaron a la Corte que fije en equidad un monto indemnizatorio por daño material, teniendo en cuenta que los miembros de la Comunidad y sus líderes han tenido que hacer numerosas gestiones y desplazamientos durante los años que ha durado el proceso de reivindicación. El Estado consideró que no hay relación entre el petitorio de la Comunidad relacionada a las indemnizaciones reclamadas y los hechos denunciados. 317. La Corte encuentra que las acciones y gestiones realizadas por los miembros de la Comunidad generaron gastos que deben ser considerados como daño emergente, en particular en lo referente a las acciones o diligencias realizadas para la reclamación de su tierra, por lo que sus lideres o miembros han tenido que desplazarse para efectuar dichas diligencias ${ }^{9}$.

Precisado que a criterio de la Corte las costas son un tipo de reparación distinto de las indemnizaciones (conclusión que también se desprende de su tratamiento autónomo respecto de las referidas indemnizaciones en las resoluciones de fondo de

8 Corte Interamericana de Derechos Humanos, Corte IDH, Caso Bueno-Alves vs. Argentina, Sentencia de 11 de mayo de 2007, Fondo, reparaciones y costas, Serie C 164, párrafo 193. Disponible en: http://www.corteidh.or.cr/docs/casos/articulos/seriec_164_esp.pdf

9 Corte Interamericana de Derechos Humanos, Corte IDH, Caso Comūnidād Indigena Xákmok Kásek vs. Paraguay, Sentencia de 24 de agosto de 2010, Fondo, reparaciones y costas, Serie C 214, párrafos 316, 317. Disponible en: http://www.corteidh.or.cr/docs/casos/articulos/se riec_214_esp.pdf. En igual sentido, Corte Interamericana de Derechos Humanos, Corte IDH, Caso Vélez-Loor vs. Panamá, Sentencia de 23 de noviembre de 2010, Excepciones preliminares, fondo, reparaciones y costas, Serie C 218, párrafo 306. Disponible en: http://www.corteidh. or.cr/docs/casos/articulos/seriec_218_esp2.pdf 
esa Cámara Continental), es menester señalar qué rubros son cubiertos por este tipo de reparación, teniendo claro que el análisis que se ofrecerá a continuación se enmarca en un proceso conocido por un Tribunal Internacional, que necesariamente estuvo precedido por un procedimiento ante la Comisión Interamericana de Derechos Humanos y que, adicionalmente, previo a la presentación del caso específico ante instancias internacionales, en el ámbito nacional se tramitaron uno o varios procesos judiciales respecto del mismo asunto.

En lo que hace a los gastos cubiertos por las costas, el Tribunal ha precisado: "142. Los gastos y costas comprenden los generados tanto ante las autoridades de la jurisdicción interna, como ante el Sistema Interamericano"10. En esta misma dirección, la Corte también ha considerado: "317. Por otro lado, la Corte observa que el trámite de este caso a nivel interno e internacional ha llevado aproximadamente 20 años, tiempo durante el cual las víctimas y sus representantes han aportado su trabajo. La Corte considera razonable que durante ese lapso hayan incurrido en gastos de litigio, comunicación, transporte y suministros, entre otros"11.

En las consideraciones jurisprudenciales recién apuntadas no parece haber una contradicción. Como se indicó, la Corte otorga costas por las gestiones de las víctimas en los procesos internos y en el proceso internacional. Lo anterior es plenamente coherente, si se considera que el trámite supraestatal es una consecuencia de la imposibilidad de encontrar una solución en la jurisdicción interna. Pese a lo anterior, también se debe destacar que el Tribunal Continental en no pocas oportunidades se ha referido a la autonomía existente entre los procedimientos internos y el proceso internacional, esto bajo consideraciones puramente

10 Corte Interamericana de Derechos Humanos, Corte IDH, Caso Vera-Vera y otra vs. Ecuador, Sentencia de 19 de mayo de 2011, Excepción preliminar, fondo, reparaciones y costas, Serie C 226, párrafo 142. Disponible en: http://www.corteidh.or.cr/docs/casos/articulos/seriec_226_esp. pdf

11 Corte Interamericana de Derechos Humanos, Corte IDH, Caso Masacres de Río Negro vs. Guatemala, Sentencia de 4 de septiembre de 2012, Excepción preliminar, fondo, reparaciones y costas, Serie C 250. Disponible en: http://www.corteidh.or.cr/docs/casos/articulos/ seriec_250_esp.pdf 
formales, a saber: el objeto de los procesos y las partes, que en ambos tipos de procesos (los internos y los internacionales), son distintos.

Refiriéndose a la teoría de la cuarta instancia, la Corte Interamericana en muchas oportunidades ha aclarado que ese órgano jurisdiccional no es una instancia adicional del proceso interno tramitado dentro del Estado demandado, es decir, que el trámite ante el Tribunal no es una tercera o cuarta instancia respecto de un proceso nacional previo ${ }^{12}$.

Bajo esta tesitura, es claro que los costos de los gastos en los que incurrieron las presuntas víctimas en procura de justicia dentro del Estado, deberían ser tenidos como daños, pues al tratarse de procesos autónomos, el reconocimiento de costas en el trámite internacional por gastos derivados de procesos internos, sería lo mismo que reconocer que se están otorgando costas en un proceso en razón de gastos producidos en otro. La rigurosidad lógica de aceptar la teoría de la cuarta instancia en términos tan irrestrictos como lo ha pregonado la Corte Interamericana, debería llevar a la conclusión a la que excepcionalmente ha arribado ese Tribunal, respecto a que los gastos por búsqueda de justicia en la jurisdicción interna deberían ser reconocidos como reparaciones por daños distintas de las costas otorgadas por concepto de proceso supranacional.

Por otro lado, una segunda consecuencia derivada de la inclusión de las costas como parte del concepto de reparaciones, es que su otorgamiento es procedente únicamente en favor de las víctimas declaradas en sentencia. El resultado de esta construcción teórica es la improcedencia de ordenar el pago de las costas en favor del Estado demandado cuando el proceso es archivado

12 Sobre este tema, Corte Interamericana de Derechos Humanos, Corte IDH, Caso Granier y otros (Radio Caracas Televisión) vs. Venezuela, Sentencia de 22 de junio de 2015, Excepciones preliminares, fondo, reparaciones y costas, Serie C 293, párrafo 294. Disponible en: http://www. corteidh.or.cr/docs/casos/articulos/seriec_293_esp.pdf 
en razón del acogimiento de una excepción preliminar ${ }^{13}$, o bien en el supuesto de ser desestimado por razones de fondo ${ }^{14}$.

De los escasos procesos en los que la Corte Interamericana de Derechos Humanos ha decretado el archivo de un caso, sin establecer ningún tipo de responsabilidad internacional del Estado demandado, solamente en el caso Castillo González y otros vs. Venezuela, hubo una breve referencia al tema de las costas, pues en el punto 4 de la parte dispositiva de la sentencia de fondo, el Tribunal continental señaló: “4. Al no haberse establecido la responsabilidad internacional del Estado, no procede pronunciarse sobre reparaciones, costas y gastos"15.

Por último, es menester indicar que en el proceso ante la Corte, no se hace ninguna distinción entre costas personales y procesales, pues a partir del estudio detallado de la jurisprudencia del Tribunal, es claro que estos conceptos no son asimilables con los de costas y gastos, que se utilizan frecuentemente con poca rigurosidad técnica.

Así las cosas, la conceptualización hecha por la Corte sobre las costas en su jurisprudencia plantea dos aspectos a considerar. En primer término, entender que las costas son reparaciones

13 Sobre este particular, Corte Interamericana de Derechos Humanos, Corte IDH, Caso Alfonso Martín del Campo-Dodd vs. México, Sentencia de 3 de septiembre de 2004, Excepciones preliminares, Serie C 113. Disponible en: http://www.corteidh.or.cr/docs/casos/articulos/ seriec_113_esp.pdf y Corte Interamericana de Derechos Humanos, Corte IDH, Caso BrewerCarías vs. Venezuela, Sentencia de 26 de mayo de 2014, Excepciones preliminares, Serie C 278. Disponible en: http://www.corteidh.or.cr/docs/casos/articulos/seriec_278_esp.pdf

14 Sobre este particular, Corte Interamericana de Derechos Humanos, Corte IDH, Caso FairénGarbi y Solis-Corrales vs. Honduras, Sentencia de 15 de marzo de 1989, Fondo, Serie C 6. Disponible en: http://www.corteidh.or.cr/docs/casos/articulos/seriec_06_esp.pdf. Corte Interamericana de Derechos Humanos, Corte IDH, Caso Nogueira de Carvalho y otro vs. Brasil, Sentencia de 28 de noviembre de 2006, Excepciones preliminares y fondo, Serie C 161. Disponible en: http://www.corteidh.or.cr/docs/casos/articulos/seriec_161_esp1.pdf. Corte Interamericana de Derechos Humanos, Corte IDH, Caso Grande vs. Argentina, Sentencia de 31 de agosto de 2011, Excepciones preliminares y fondo, Serie C 231. Disponible en: http://www.corteidh. or.cr/docs/casos/articulos/seriec_231_esp.pdf. Corte Interamericana de Derechos Humanos, Corte IDH, Caso Palma-Mendoza y otros vs. Ecuador, Sentencia de 3 de septiembre de 2012, Excepción preliminar y fondo, Serie C 247. Disponible en: http://www.corteidh.or.cr/docs/ casos/articulos/seriec_247_esp.pdf. Corte Interamericana de Derechos Humanos, Corte IDH, Caso Castillo-González y otros vs. Venezuela, Sentencia de 27 de noviembre de 2012, Fondo, Serie C 256. Disponible en: http://www.corteidh.or.cr/docs/casos/articulos/seriec_256_esp.pdf

15 Corte Interamericana de Derechos Humanos, Corte IDH, Caso Castillo-González y otros vs. Venezuela, Sentencia de 27 de noviembre de 2012, Fondo, Serie C 256. Disponible en: http:// www.corteidh.or.cr/docs/casos/articulos/seriec_256_esp.pdf 
conferidas a las víctimas de violaciones de Derechos Humanos precisadas en la resolución de fondo por gastos en el proceso interno, el cual según la propia Corte es independiente del trámite supraestatal, implica reconocer que se están otorgando costas en un proceso en razón de gastos producidos en otro. Por otra parte, la conceptualización utilizada por el Tribunal internacional también lleva a negar el otorgamiento de costas en favor de los Estados en casos en que los procesos sean archivados sin el establecimiento de ningún tipo de responsabilidad internacional por violaciones de Derechos Humanos.

\author{
III. El tratamiento de las costas en el Sistema \\ INTERAMERICANO ES INDEPENDIENTE DE LAS REGULACIONES \\ INTERNAS DEL ESTADO DEMANDADO EN ESA MATERIA
}

\begin{abstract}
A la fecha, la Corte ha sostenido el criterio de la existencia de una autonomía entre los institutos y conceptos jurídicos del Derecho Internaciona ${ }^{16}$, respecto de aquellos con denominaciones
\end{abstract}

16 Sobre este particular en un primer momento el juez Antônio Augusto Cançado-Trindade precisó: "33. (...) Así, en materia de tratados de derechos humanos, cabe tener siempre presente el carácter objetivo de las obligaciones que encierran, el sentido autónomo (en relación con el derecho interno de los Estados) de los términos de dichos tratados, la garantía colectiva subyacente a estos, el amplio alcance de las obligaciones de protección y la interpretación restrictiva de las restricciones permisibles". Corte Interamericana de Derechos Humanos, Corte IDH, Caso Blake vs. Guatemala, Sentencia de 22 de enero de 1999, Reparaciones y costas, Serie C 48, Voto razonado del juez Antônio Augusto Cançado-Trindade. Disponible en: http://www. corteidh.or.cr/docs/casos/articulos/seriec_48_esp.pdf. Posteriormente, el juez Eduardo Ferrer Mac-Gregor Poisot, repasando los criterios de la Corte en esta materia señaló: "11. A través de una interpretación evolutiva, la Corte sostuvo que: '[1]os términos de un tratado internacional de derechos humanos tienen sentido autónomo, por lo que no pueden ser equiparados al sentido que se les atribuye en el derecho interno. Además, dichos tratados de derechos humanos son instrumentos vivos cuya interpretación tiene que adecuarse a la evolución de los tiempos y, en particular, a las condiciones de vida actuales'. El Derecho a la Información sobre la Asistencia Consular en el Marco de las Garantías del Debido Proceso Legal. Opinión Consultiva OC-16/99 de 1 de octubre de 1999. Serie A No. 16, párr. 114". Corte Interamericana de Derechos Humanos, Corte IDH, Caso de los Pueblos Indígenas Kuna de Madungandí y Emberá de Bayano y sus miembros vs. Panamá, Sentencia de 14 de octubre de 2014, Excepciones preliminares, fondo, reparaciones y costas, Serie C 284, voto parcialmente disidente del juez Eduardo Ferrer MacGregor Poisot. Disponible en: http://www.corteidh.or.cr/docs/casos/articulos/seriec_284_esp. pdf. Corte Interamericana de Derechos Humanos, Corte IDH, Opinión Consultiva OC̄-16/99 de 1 de octubre de 1999, solicitada por los Estados Unidos Mexicanos, Serie A 16, El Derecho a la Información sobre la Asistencia Consular en el Marco de las Garantías del Debido Proceso Legal. Disponible en: http://www.corteidh.or.cr/docs/opiniones/seriea_16_esp.pdf 
similares en el derecho interno de los distintos Estados que voluntariamente se han sometido a la jurisdicción de ese Tribunal.

Esta posición tiene sentido por cuanto un mismo instituto jurídico puede presentar importantes variaciones de un ordenamiento nacional a otro. En esta dirección, la Corte ha señalado: “77. (...) Esta consideración se fortalece si se recuerda que, como ha manifestado la Corte en otras ocasiones, las formalidades características de ciertas ramas del derecho interno no rigen en el derecho internacional de los derechos humanos, cuyo principal y determinante cuidado es la debida y completa protección de esos derechos"17.

En materia de otorgamiento de costas, el Tribunal Continental se ha pronunciado expresamente en el sentido de que las regulaciones internas sobre ese particular no limitan la competencia de la Corte. En esa dirección, ha considerado: "193. En el presente caso, los representantes no han remitido al Tribunal prueba que respalde su pretensión en materia de costas y gastos. Por otro lado, respecto a la valoración de su monto, el Tribunal no se encuentra sujeto a lo que determine la legislación interna de los Estados. Por ello, la estimación presentada por los representantes no es la adecuada ni su monto es razonable"18.

Pese a la claridad de la línea argumentativa anterior, esa instancia jurisdiccional continental también se ha separado de la legislación interna, justificando por qué esta no le es aplicable en el caso concreto y no sosteniendo su autonomía en la materia. A manera de ejemplo, se tiene que esa Cámara supraestatal también ha razonado:

290. La Corte da por establecido que la familia Ibsen y sus representantes incurrieron en gastos durante el procedimiento interno e internacional del presente caso. En particular, el Tribunal toma en cuenta que la señora Rebeca Ibsen-Castro se ha encargado de impulsar el caso durante más de

17 Corte Interamericana de Derechos Humanos, Corte IDH, Caso Castillo-Petruzzi y otros vs. Perú, Sentencia de 4 de septiembre de 1998, Excepciones preliminares, Serie C 41, párrafo 77. Disponible en: http://www.corteidh.or.cr/docs/casos/articulos/seriec_41_esp.pdf

18 Corte Interamericana de Derechos Humanos, Corte IDH, Caso Bayarri vs. Argentina, Sentencia de 30 de octubre de 2008, Excepción preliminar, fondo, reparaciones y costas, Serie C 187, párrafo 193. Disponible en: http://www.corteidh.or.cr/docs/casos/articulos/seriec_187_esp.pdf 
diez años a nivel interno. Así, en cuanto a las objeciones planteadas por Estado, el Tribunal observa que el arancel del Colegio de Abogados de La Paz citado por aquel (supra párr. 287) establece para el año 2005 los horarios profesionales mínimos, mas no los máximos, que debian cobrar los abogados desempeñándose en distintas materias, entre estas, la materia penal. Por tanto, dicho documento no es útil para ilustrar al Tribunal sobre la cantidad que debe fijarse en este rubro ${ }^{19}$.

Consideraciones como la expuesta siembran enormes dudas respecto de cuál habría sido la posición de la Corte en el caso concreto, si "el arancel del Colegio de Abogados de La Paz", amén de regular mínimos, también tuviera disposiciones respecto de montos máximos a cancelar por concepto de honorarios.

\section{Costas y SUJETOS PROCESAles}

La particular evolución que ha vivido el Sistema Interamericano, hace que el proceso ante la Corte continental no tenga paralelo con el resto de sistemas continentales (africano y europeo), y menos aún con el Sistema Universal de Protección de Derechos Humanos.

A la fecha, en el proceso ante la Corte, hay dos partes (la demandante y la demandada). La primera conformada por la Comisión Interamericana de Derechos Humanos, que somete el proceso ante el Tribunal para velar por el orden público interamericano ${ }^{20}$. En este punto es importante destacar que el Reglamento de la Corte otorga un cierto grado de participación a las presuntas víctimas en el proceso que, sin constituirse como una parte en sentido estricto, sí participan en la causa con auto-

19 Corte Interamericana de Derechos Humanos, Corte IDH, Caso Ibsen-Cárdenas e Ibsen-Peña vs. Bolivia, Sentencia de 1 de septiembre de 2010, Fondo, reparaciones y costas, Serie C No. 217, párrafo 290. Disponible en: http://www.corteidh.or.cr/docs/casos/articulos/seriec_217_esp1. pdf

20 Sobre el instituto del Orden Público Interamericano, Corte Interamericana de Derechos Humanos, Corte IDH, Caso Mémoli vs. Argentina, Sentencia de 22 de agosto de 2013, Excepciones preliminares, fondo, reparaciones y costas, Serie C 265, párrafo 14. Disponible en: http://www. corteidh.or.cr/docs/casos/articulos/seriec_265_esp.pdf. Corte Interamericana de Derechos Humanos, Corte IDH, Caso Masacre de Santo Domingo vs. Colombia, Sentencia de 30 de noviembre de 2012, Excepciones preliminares, fondo y reparaciones, Serie C 259, párrafo 17. Disponible en: http://www.corteidh.or.cr/docs/casos/articulos/seriec_259_esp.pdf 
nomía en algunos temas (alegatos de derecho, demostración de daños y perjuicios y cuantificación de las reparaciones ${ }^{21}$. En el otro lado de la relación jurídico-procesal, la parte demandada está integrada únicamente por el Estado o Estados demandados.

Como fue referido supra, al ser las costas un componente de las reparaciones, nunca beneficiarían a la parte demandada que en tal condición no ha pretendido ningún tipo de reparación, aspecto que a la fecha sería impensable pues en el proceso ante la Corte no es admisible el instituto de la contrademanda o reconvención, ni siquiera en materia de costas.

Más simple, en el Sistema Interamericano de Protección de Derechos Humanos no es posible que un Estado que no haya sido condenado en un proceso del que ha sido parte demandada, sea indemnizado por las costas y gastos que incurrió para afrontar ese proceso.

En lo que hace a los sujetos que — en sentido genérico - integran la parte demandante, a saber: las presuntas víctimas y la Comisión Interamericana, su tratamiento es distinto según quién requiera el resarcimiento de costas. Esta diferencia de trato será analizada más adelante.

21 Sobre la autonomía procesal de las presuntas víctimas, la Corte Interamericana de Derechos Humanos ha considerado: "32. Por otro lado, es jurisprudencia reiterada del Tribunal que las presuntas víctimas y sus representantes pueden invocar la violación de otros derechos distintos a los ya comprendidos en la demanda siempre y cuando se atengan a los hechos ya contenidos en la demanda, en tanto son las presuntas víctimas las titulares de todos los derechos consagrados en la Convención. En efecto, la demanda constituye el marco fáctico del proceso ante la Corte, por lo que no es admisible alegar nuevos hechos distintos de los planteados en dicho escrito, sin perjuicio de exponer aquellos que permitan explicar, aclarar o desestimar los que han sido mencionados en la demanda, o bien, responder a las pretensiones del demandante. La excepción a este principio son los hechos que se califican como supervinientes, que podrán ser remitidos al Tribunal en cualquier estado del proceso antes de la emisión de la sentencia. Por otra parte, el momento para que las presuntas víctimas o sus representantes ejerzan plenamente aquel derecho de locus standi in judicio es el escrito de solicitudes y argumentos. En definitiva, corresponde a la Corte decidir en cada caso acerca de la procedencia de alegatos de tal naturaleza en resguardo del equilibrio procesal de las partes". Corte Interamericana de Derechos Humanos, Corte IDH, Caso Vera-Vera y otra vs. Ecuador, Sentencia de 19 de mayo de 2011, Excepción preliminar, fondo, reparaciones y costas, Serie C 226, párrafo 32. Disponible en: http://www.corteidh.or.cr/docs/casos/articulos/seriec_226_esp.pdf 


\section{Procedencia de Las Costas SEgún}

EL TIPO DE REPRESENTACIÓN

Comentada la improcedencia de las costas en favor de los Estados demandados no condenados, a partir de este momento se abordará el tema de la procedencia del otorgamiento de las costas.

Sin lugar a dudas, el primer elemento que debe puntualizarse es el tipo de representación con que las presuntas víctimas han litigado ante la Corte Interamericana, pues si bien es cierto materialmente se trata de abogados, estos pueden participar en el respectivo proceso: en el ejercicio liberal de su profesión como abogados litigantes, como trabajadores de una organización no gubernamental o como funcionarios públicos nacionales e incluso como funcionarios internacionales. La condición apuntada será el primer aspecto que determinará la procedencia de las costas a otorgar.

\section{A. Representación a cargo de la Comisión Interamericana}

La primera controversia respecto de las costas se estableció al inicio de la función contenciosa de la Corte. En aquel momento, la Comisión era el único sujeto procesal que integraba la parte demandante y procuraba justicia internacional para las presuntas víctimas de violaciones de Derechos Humanos.

Por lo anterior, el tema de la procedencia de las costas en razón de las labores de litigio llevadas a cabo por la Comisión ante la Corte Continental en representación de los intereses de las víctimas, fue el primer conflicto que en esta materia debió resolver la Corte. Respecto de este particular, el Tribunal consideró:

113. La Convención Americana ha instituido un sistema para la protección de los derechos humanos en el continente y ha atribuido funciones principalmente a dos órganos, la Comisión y la Corte, cuyos costos se financian dentro del presupuesto de la Organización de los Estados Americanos. 114. La Comisión ha preferido, en este proceso, cumplir las funciones que la Convención Americana le impone recurriendo a la contratación de profesionales 
en lugar de hacerlo con su personal propio. Esta modalidad de trabajo de la Comisión es una cuestión de organización interna en la cual la Corte no debe intervenir. Pero la Comisión no puede exigir el reintegro de los gastos que le exige su modalidad interna de trabajo a través de la imposición de costas. El funcionamiento de los órganos del sistema americano de derechos humanos es pagado por los Estados Miembros mediante su cuota anual. La Corte tampoco podría imponer como costas los gastos de viaje de su Secretaria adjunta a Suriname, ni el asesoramiento requerido en materia económica o actuarial, pues se trata de gastos que el Tribunal debe hacer como órgano del Sistema para cumplir debidamente con las funciones que la Convención Americana le impone ${ }^{22}$.

El criterio anterior también ha sido el seguido por la Corte para las labores realizadas por la Comisión Interamericana en fases posteriores al dictado de la sentencia de fondo y reparaciones $^{23}$.

\section{B. Representación a cargo de funcionarios públicos nacionales}

La procedencia de las costas en supuestos en los que la representación de las presuntas víctimas estuvo a cargo de instituciones públicas nacionales en dos modalidades no tardó muchos años en requerir un pronunciamiento de la Corte Interamericana. En primer término, en supuestos en los que el patrocinio letrado estuvo a cargo de la Defensa Pública Interna. En segundo lugar están los casos en los que la representación fue responsabilidad de las instituciones nacionales tipo Defensorías del Pueblo $\mathrm{u}$ Ombudsman.

En aquellos asuntos en los que en el proceso supranacional el patrocinio letrado estuvo a cargo de defensores públicos internos, la Corte ha considerado: "131. La Corte aprecia que el señor Fermín Ramírez fue defendido en el ámbito interno por el Instituto de Defensa Pública, al que se asigna un presupuesto

22 Corte Interamericana de Derechos Humanos, Corte IDH, Caso Aloeboetoe y otros vs. Surinam, Sentencia de 10 de septiembre de 1993, Reparaciones y costas, Serie C 15, párrafos 113, 114. Disponible en: http://www.cidh.oas.org/Indigenas/seriec_15_esp.pdf

23 Corte Interamericana de Derechos Humanos, Corte IDH, Caso Caballero-Delgado y Santana vs. Colombia, Sentencia de 29 de enero de 1997, Reparaciones y costas, Serie C 31, párrafo 59. Disponible en: http://www.corteidh.or.cr/docs/casos/articulos/seriec_31_esp.pdf 
público específico. En el presente caso, la asistencia brindada y los gastos asumidos por dicho Instituto están previstos dentro de sus obligaciones y presupuesto. En consecuencia, no procede ordenar el reintegro de costas y gastos realizados por el Instituto de Defensa Pública"24.

Ocho años más tarde, la Corte volvió a denegar el otorgamiento de costas en el marco de un proceso en contra de otro Estado bajo la misma línea argumentativa. En esta segunda oportunidad, el Tribunal continental consideró: "359. No obstante, en este caso, la Corte observa que la representante de las víctimas es la titular de la Defensoría General de la Nación de Argentina, la cual forma parte de los órganos del Estado. La representante no justificó cómo, a pesar de esta circunstancia, sería procedente el reintegro de las cantidades solicitadas. Por lo tanto, el Tribunal no ordenará el reintegro de los gastos alegados" 25 .

Por su parte, cuando la procuración de justicia de los intereses de las víctimas estuvo a cargo de la Defensoría del Pueblo, la Corte también ha denegado la procedencia de la condena en costas al Estado vencido. En esa dirección, esa instancia ha considerado:

181. (...) Teniendo en cuenta las consideraciones anteriores y al no contar con prueba documental que acredite los gastos en que incurrieron las victimas y el representante por las gestiones efectuadas en el procedimiento interno, la Corte determina en equidad que el Estado debe entregar la cantidad de US\$1.500,00 (un mil quinientos dólares de los Estados Unidos de América) a Hugo Ticona, por concepto de costas y gastos. Cabe señalar, que este Tribunal para la fijación de los gastos y costas ha excluido las erogaciones incurridas a nivel internacional, ya que en el proceso ante el Sistema Interamericano del presente caso el Defensor del Pueblo fue el representante de las víctimas y como se desprende de lo manifestado por él y por el Estado, dichas actuaciones son gratuitas. (...) Por último,

24 Corte Interamericana de Derechos Humanos, Corte IDH, Caso Fermín Ramírez vs. Guatemala, Sentencia de 20 de junio de 2005, Fondo, reparaciones y costas, Serie C 126, párrafo 131. Disponible en: http://www.corteidh.or.cr/docs/casos/articulos/seriec_126_esp.pdf

25 Corte Interamericana de Derechos Humanos, Corte IDH, Caso Mendoza y otros vs. Argentina, Sentencia de 14 de mayo de 2013, Excepciones preliminares, fondo y reparaciones, Serie C 260, párrafo 359. Disponible en: http://www.corteidh.or.cr/docs/casos/articulos/resumen_260_esp. pdf 
esta Corte valora positivamente la participación del Defensor del Pueblo en el presente proceso internacional, ya que fortalece la tutela general de los derechos humanos y por consiguiente, el Sistema Interamericano de Protección de los Derechos Humanos ${ }^{26}$.

\section{Representación a cargo de abogados litigantes u $O N G$}

Por su parte, en aquellos supuestos en los que la representación de las presuntas víctimas ha estado a cargo de profesionales independientes, la Corte no ha objetado la procedencia de la condena al pago de costas por esa sola circunstancia, lo anterior, sin perjuicio de las consideraciones que en adelante se exponen.

Así a manera de conclusión preliminar se puede indicar que no es procedente la condena en este rubro, en lo que hace a los gastos de patrocinio en el proceso ante la Corte Continental cuando las presuntas víctimas estén representadas por la Comisión Interamericana de Derechos Humanos, o por instituciones públicas nacionales, sean Defensorías o Procuraciones Públicas, o instituciones Defensoras de Derechos Humanos tipo Defensorías del Pueblo u Ombudsman. Por otra parte, sí es procedente el pago de costas cuando el patrocinio letrado haya estado a cargo de profesionales independientes u organizaciones no gubernamentales.

\section{CRITERIOS PARA LA CUANTIFICACIÓN DE LOS HONORARIOS PROFESIONALES QUE HACEN PARTE DE LAS COSTAS}

A finales de la década de los noventa, la Corte estableció un primer elenco de parámetros para la cuantificación de los honorarios de los representantes en el proceso ante el Sistema Interamericano. En aquel momento, el Tribunal consideró:

26 Corte Interamericana de Derechos Humanos, Corte IDH, Caso Ticona-Estrada y otros vs. Bolivia, Sentencia de 27 de noviembre de 2008, Fondo, reparaciones y costas, Serie C 191, párrafo 181. Disponible en: http://www.corteidh.or.cr/docs/casos/expedientes/seriec_191_esp. pdf 
83. La Corte no estima adecuado que la regulación de costas deba guardar una proporción con el monto de la indemnización obtenida. Existen otros elementos que son más importantes para valorar la actuación de los abogados en un proceso ante un tribunal internacional, como, por ejemplo, el aporte de pruebas que tiendan a demostrar los hechos expuestos en la demanda, el conocimiento acabado de la jurisprudencia internacional y, en general, todo aquello que permita evaluar la calidad y pertinencia del trabajo efectuado ${ }^{27}$.

Algunos años después, la misma Corte revisó los criterios recién planteados y amplió la lista de aspectos a considerar en este tema en particular. En este sentido, esa instancia incrementó los parámetros referidos en los siguientes términos:

214. En cuanto a la posición señalada por el Estado, en el sentido de determinar las costas en proporción al monto de la indemnización obtenida por las víctimas o sus familiares, la Corte estima insuficiente dicho procedimiento, por cuanto existen otros elementos que permiten evaluar la calidad y pertinencia del trabajo efectuado, tales como el aporte de elementos probatorios para sustentar los hechos expuestos por las partes, el consejo legal que brinde a sus representados, la diligencia en el cumplimiento de las distintas gestiones procedimentales ante el Tribunal y el grado de conocimiento de la jurisprudencia internacional ${ }^{28}$.

Antes de abordar el tema de la procedencia de los contratos de cuotalitis y la práctica de establecer los honorarios en razón de porcentajes de los daños concedidos, cabe señalar que en el proceso ante la Corte Interamericana también se han establecido honorarios parciales por la participación durante una parte del proceso. Así en un caso en el que el representante que inició el trámite, falleció antes de la finalización del juicio, el Tribunal otorgó costas parciales a los derechohabientes de dicho profesional y otro porcentaje al profesional que asumió el patrocinio de las víctimas. En aquel asunto el Tribunal Continental precisó:

27 Corte Interamericana de Derechos Humanos, Corte IDH, Caso Garrido y Baigorria vs. Argentina, Sentencia de 27 de agosto de 1998, Reparaciones y costas, Serie C 39, párrafo 83. Disponible en: http://www.corteidh.or.cr/docs/casos/articulos/seriec_39_esp.pdf

28 Corte Interamericana de Derechos Humanos, Corte IDH, Caso de la "Panêl Blanca" (PaniaguaMorales y otros) vs. Guatemala, Sentencia de 25 de mayo de 2001, Reparaciones y Costas, Serie C 76. Disponible en: http://www.corteidh.or.cr/docs/casos/articulos/Seriec_76_esp.pdf 
373. Por consiguiente, la Corte fija en equidad la cantidad de US\$10.000 (diez mil dólares de los Estados Unidos de América) por concepto de costas y gastos a favor del representante G.T., la cual deberá ser pagado directamente a sus derechohabientes, conforme al derecho interno aplicable. Asimismo, la Corte establece en equidad la cantidad de US\$2.000 (dos mil dólares de los Estados Unidos de América) por concepto de costas y gastos a favor del representante May y la cantidad de US\$3.000 (tres mil dólares de los Estados Unidos de América) por concepto de costas y gastos a favor del representante Molina ${ }^{29}$.

\section{Contratos de cuotalitis}

A pesar de lo indicado por la Corte respecto a la inconveniencia de establecer honorarios a partir de cálculos porcentuales de las indemnizaciones otorgadas, aspecto referenciado en las citas de precedentes incorporadas en el apartado anterior, en lo que hace al tema de los contratos de cuotalitis, la Corte ha señalado un único supuesto en el que esa instancia interviene en este tipo de relación contractual entre las presuntas víctimas y los abogados representantes. Haciendo la precisión apuntada, el Tribunal ha establecido: " 280 . La Corte ha señalado anteriormente que no tiene competencia para pronunciase [sic] sobre los acuerdos que las víctimas lleguen con sus representantes en materia de honorarios profesionales. Sin embargo, si como en el presente caso se solicita al Tribunal que ese acuerdo entre víctimas y representantes sea asumido por el Estado, la Corte deberá analizar si el quantum del mismo es razonable" 30 .

No obstante lo anterior, en casos posteriores, el mismo Tribunal ha entendido innecesario hacer consideraciones en materia de costas, justamente en razón de la existencia de un contrato de cuotalitis. En esa oportunidad, el Tribunal precisó:

29 Corte Interamericana de Derechos Humanos, Corte IDH, Caso Artavia-Murillo yotros (Fecundación in vitro) vs. Costa Rica, Sentencia de 28 noviembre de 2012, Excepciones preliminares, fondo, reparaciones y costas, Serie C 257. Disponible en: http://www.corteidh.or.cr/docs/casos/ articulos/seriec_257_esp.pdf

30 Corte Interamericana de Derechos Humanos, Corte IDH, Caso Chaparro-Álvarez y LapoÍñiguez vs. Ecuador, Sentencia de 21 de noviembre de 2007, Excepciones preliminares, fondo, reparaciones y costas, Serie C 170, párrafo 280. Disponible en: http://www.corteidh.or.cr/docs/ casos/articulos/seriec_170_esp.pdf 
289. En consideración de todo lo anterior y las observaciones del Estado, la Corte fija en equidad una cantidad total de US\$10.000,00 (diez mil dólares de Estados Unidos de América) por concepto de gastos en el litigio del presente caso. Dicha cantidad deberá ser liquidada por el Estado a Pedro Chitay, la cual entregará a quienes corresponda. Dicho monto incluye los gastos futuros en que pueda incurrir a nivel interno o durante la supervisión de cumplimiento de esta Sentencia los miembros de la familia Chitay-Rodríguez y sus representantes. En este caso debido a que la representante legalmente acreditada acordó con las víctimas una cuota litis como honorario, según consta en el contrato de representación, este Tribunal no se pronunciará al respecto ${ }^{31}$.

Aquí se debe destacar que, pese a la posición adoptada por la Corte en el párrafo anterior, el Tribunal posteriormente estableció la imputación de los honorarios pactados por concepto de cuotalitis, al rubro de costas otorgadas en sentencia, sin revisar los alcances de aquel contrato de representación. En esa oportunidad, esa instancia judicial ordenó lo siguiente:

259. Teniendo en cuenta las anteriores consideraciones, así como el acervo probatorio, la Corte determina en equidad que el Estado debe entregar la cantidad de US\$35.000,00 (treinta y cinco mil dólares de los Estados Unidos de América) al señor Iván Cepeda-Castro, para que este la entregue a los respectivos representantes por concepto de costas y gastos incurridos ante la Comisión y ante este Tribunal. Estos montos incluyen los gastos futuros en que puedan incurrir las víctimas durante la supervisión del cumplimiento de esta Sentencia. Si hubiere un pacto de cuota litis entre los representantes y las víctimas, el monto pactado deberá imputarse al pago del monto establecido por concepto de costas y gastos ${ }^{32}$.

\section{En síntesis, si bien la Corte ha dado cabida en sus procesos} al instituto de la cuotalitis, su tratamiento ha sido casuístico,

31 Corte Interamericana de Derechos Humanos, Corte IDH, Caso Chitay-Nech y otros vs. Guatemala, Sentencia de 25 de mayo de 2010, Excepciones preliminares, fondo, reparaciones y costas, Serie C 212, párrafo 289. Disponible en: http://www.corteidh.or.cr/docs/casos/articulos/ seriec_212_esp.pdf

32 Corte Interamericana de Derechos Humanos, Corte IDH, Caso Manuel Cepeda-Vargas vs. Colombia, Sentencia de 26 de mayo de 2010, Excepciones preliminares, fondo, reparaciones y costas, Serie C 213, párrafo 259. Disponible en: http://www.corteidh.or.cr/docs/casos/articulos/ seriec_213_esp.pdf 
situación que no permite establecer claramente los alcances de ese contrato ante este Tribunal.

\section{EXONERACIÓN DEL PAGO DE COSTAS AL ESTADO DEMANDADO}

En este apartado, se analizarán los criterios sentados por el Tribunal para aquellos casos en los que siendo posible la condena en costas a la parte demandada, se resolvió la improcedencia de tal condena en razón de las consideraciones que serán expuestas a continuación.

\section{A. Consideraciones respecto de la exoneración total}

En los albores del funcionamiento del Tribunal Supranacional, esta instancia estableció un supuesto en el que la condenatoria al pago de costas no es procedente. Así, a inicios de la década de los noventa, la Corte consideró: "115. Habida consideración de lo anterior y de que Suriname ha reconocido expresamente su responsabilidad internacional y no ha dificultado el procedimiento para determinar las reparaciones, la Corte desestima la solicitud de condenación en costas pedida por la Comisión"33.

No obstante el estándar establecido en dicho precedente, quince años después ante un requerimiento de otro Estado alegando la misma situación fáctica, la Corte consideró:

131. El Estado solicitó que "se valore la asunción de responsabilidad internacional, a la hora de determinar las eventuales costas". En este sentido, citó el siguiente párrafo de la Sentencia de reparaciones y costas emitida en el caso Aloeboetoe y otros vs. Suriname: "Habida consideración de lo anterior y de que Suriname ha reconocido expresamente su responsabilidad internacional y no ha dificultado el procedimiento para determinar las reparaciones, la Corte desestima la solicitud de condenación en costas pedida por la Comisión". 132. La Corte considera que el citado párrafo

33 Corte Interamericana de Derechos Humanos, Corte IDH, Caso Aloeboetoe y otros vs. Surinam, Sentencia de 10 de septiembre de 1993, Reparaciones y costas, Serie C 15, párrafo 115. Disponible en: http://www.cidh.oas.org/Indigenas/seriec_15_esp.pdf 
no tiene aplicación en el presente caso. En efecto, si bien se consideró que Suriname reconoció su responsabilidad y no entorpeció el procedimiento interamericano, esos no fueron los únicos elementos tomados en cuenta al momento de dictar la señalada Sentencia. Así, en los párrafos anteriores al citado por el Estado, el Tribunal consideró que los hechos de ese caso fueron puestos en conocimiento de la Comisión quince días después de ocurridos; que los familiares de las víctimas no necesitaron efectuar prolongadas tramitaciones para someterlo a la Comisión, pues ella se ocupó del asunto de inmediato; que no se vieron obligados a requerir el asesoramiento de un profesional; y que los gastos en que incurrió la Comisión en el trámite del caso se financian dentro del presupuesto de la Organización de Estados Americanos. Ninguno de estos elementos de juicio existe en el presente caso ${ }^{34}$.

En otro orden de ideas, muy recientemente, la Corte Interamericana sentó otro supuesto de exoneración del pago de costas al Estado demandado respecto del cual se ha determinado la existencia de una responsabilidad internacional, que se configura cuando se da la renuncia expresa de esa prerrogativa procesal. En este sentido, el Tribunal estimó lo siguiente: "247. Como ya lo ha señalado la Corte en oportunidades anteriores, las costas y gastos están comprendidos dentro del concepto de reparación establecido en el artículo 63.1 de la Convención Americana. El Tribunal observa, sin embargo, que las representantes han 'renuncia[do] a su derecho de reclamar costas legales por el litigio del presente caso'. Por tanto, la Corte considera que las costas y gastos del litigio no son objeto de disputa y no es necesario que se pronuncie sobre este punto"35.

Por último, únicamente para efectos académicos, se hace referencia a la existencia de otro supuesto de exoneración del pago de costas sentado por la Corte Interamericana a mediados de los noventa, consistente en la improcedencia de tal condenatoria, cuando la responsabilidad fue establecida en virtud de

34 Corte Interamericana de Derechos Humanos, Corte IDH, Caso Kimel vs. Argentina, Sentencia de 2 de mayo de 2008, Fondo, reparaciones y costas, Serie C 177, párrafos 131, 132. Disponible en: http://www.corteidh.or.cr/docs/casos/articulos/seriec_177_esp.pdf

35 Corte Interamericana de Derechos Humanos, Corte IDH, $\bar{C}$ aso García-Lucero yotras vs. Chile, Sentencia de 28 de agosto de 2013, Excepción preliminar, fondo y reparaciones, Serie C 267, párrafo 247. Disponible en: http://www.corteidh.or.cr/docs/casos/articulos/seriec_267_esp.pdf 
inferencias. En aquel momento, el Tribunal resolvió: “71. En virtud, igualmente, de que la responsabilidad de Suriname es inferida, la Corte considera que debe desestimar la solicitud de condenatoria en costas"36.

Pese a ser una verdad de Perogrullo, se debe indicar que en la práctica este criterio está más que superado pues a la fecha en no pocos casos se ha determinado la existencia de responsabilidades de un Estado en razón de inferencias, y no por eso se ha procedido a la exoneración del pago de costas.

B. Consideraciones respecto de la exoneración parcial

A lo largo de su historia, la Corte ha determinado la existencia de situaciones que, sin configurar un supuesto de exención de la condena en costas, sí afectan su otorgamiento pleno, siendo procedente en esos casos la reducción del monto otorgado. Estas circunstancias se pueden agrupar en dos conjuntos, a saber: a. Exoneración parcial de las costas producto de circunstancias acaecidas en los procesos internos, es decir, en la jurisdicción nacional, y b. Reducción del rubro otorgado por concepto de costas y gastos en razón de situaciones ocurridas durante la tramitación del caso en el Sistema Interamericano.

Un ejemplo de reducción de costas por eventos acaecidos en el proceso interno es el presentado en el caso Ricardo Canese vs. Paraguay, en el que el Tribunal redujo parcialmente las costas otorgadas. En esa oportunidad, esa instancia internacional estimó lo siguiente:

214. En relación con las costas y gastos originados ante los órganos judiciales internos, la Corte toma nota de que, mediante el acuerdo y sentencia $N^{o} 804$ emitido el 27 de abril de 2004 (supra párr. 69.50), la Sala Penal de la Corte Suprema de Justicia del Paraguay ordenó "imponer las costas y gastos de todo el juicio a la parte querellante", es decir, que no corresponde al señor Canese cubrir tales gastos. Por ello, el Tribunal no considera

36 Corte Interamericana de Derechos Humanos, Corte IDH, Caso Gangaram-Panday vs. Surinam, Sentencia de 21 de enero de 1994, Fondo, reparaciones y costas, Serie C 16. Disponible en: http://www.corteidh.or.cr/docs/casos/articulos/seriec_16_esp.pdf 
necesario tomar en cuenta, en la determinación de la cantidad total que el Paraguay debe reintegrar al señor Canese por concepto de costas y gastos, aquellos que se generaron en el ámbito judicial interno ${ }^{37}$.

No está de más aquí destacar el desacuerdo que se tiene con lo resuelto por el Tribunal en este asunto, esto al margen del desarrollo del fondo del caso. La inexistencia de una obligación de cancelar las costas de la parte contraria en el proceso interno, no significa en lo absoluto que la presunta víctima no haya tenido gastos propios en las instancias nacionales.

En otro orden de ideas, si bien en el apartado anterior se señaló la renuncia de los representantes como un supuesto para la exoneración total de la condena al pago de costas, a continuación, se hará referencia a que en supuestos en los que la representación de las víctimas está a cargo de dos o más organizaciones, la renuncia de una de ellas evidentemente implicará una reducción de las costas y no una exoneración total de este concepto. Respecto de este punto, la Corte ha considerado:

307. (...) Asimismo el Tribunal nota que, en el escrito de solicitudes y argumentos, CEJIL [Centro por la Justicia y el Derecho Internacional] solicitó el pago de las costas del proceso, no obstante, mediante comunicación de 8 de febrero de 2013 indicó que "a partir de ese día no continuar [ía] con la representación legal de la señora Rosa Elvira Franco-Sandoval y su familia", sin embargo no realizó ninguna solicitud sobre las costas y gastos a su favor. En virtud de ello, la Corte no se pronunciará al respecto. Teniendo en cuenta lo anterior, la Corte fija en equidad la cantidad de US\$10,000.00 (diez mil dólares de los Estados Unidos de América) que deben ser entregados a REDNOVI [Red de la No Violencia Contra las Mujeres], con motivo de los gastos por la tramitación del proceso ante el Sistema Interamericano de Derechos Humanos ${ }^{38}$.

37 Corte Interamericana de Derechos Humanos, Corte IDH, Caso Ricardo Canese vs. Paraguay, Sentencia de 31 de agosto de 2004, Fondo, reparaciones y costas, Serie C 111, párrafo 214. Disponible en: http://www.corteidh.or.cr/docs/casos/articulos/seriec_111_esp.pdf. Paraguay, Corte Suprema de Justicia, Sala Penal, Expediente: Ricardo Nicolás Canese-Krivoshein sobre difamación e injuria, Acuerdo y sentencia 804, 27 de abril de 2004. Disponible en: http://www. csj.gov.py/jurisprudencia/default.aspx?AspxAutoDetectCookieSupport=1

38 Corte Interamericana de Derechos Humanos, Corte IDH, Caso Veliz-Franco y otros vs. Guatemala, Sentencia de 19 de mayo de 2014, Excepciones preliminares, fondo, reparaciones y costas, Serie C 277, párrafo 307. Disponible en: http://www.corteidh.or.cr/docs/casos/articulos/ seriec_277_esp.pdf 


\section{Jorge Leiva-Poveda \\ C. Consideraciones respecto de la exoneración en razón de la representación pro bono}

Si bien líneas atrás se precisó que las reducciones al rubro de costas dependían de circunstancias ocurridas en los procesos internos o en el ámbito internacional, se ha estimado procedente analizar el tema de la representación pro bono, en un apartado separado, sin que ello implique una modificación de la agrupación temática recién referida.

Por sus características, la representación pro bono evidentemente puede presentarse en procesos internos, si la legislación nacional lo permite, y también es lícita en el trámite ante la Corte Interamericana de Derechos Humanos.

Ante tales circunstancias, es posible ubicar casos en los que la Corte ha exonerado completamente del concepto de costas al Estado demandado, cuando no ha existido pedimento en esta dirección porque se litigó mediante una representación pro bono. También es posible referenciar procesos en los que ese tipo de representación únicamente provocó una reducción parcial de tal concepto. Un ejemplo del primer supuesto es el siguiente criterio esbozado por la Corte: "135. Dado que los representantes no solicitaron ni gastos ni costas ante la Corte, ya que están actuando pro bono, y la Comisión no ha presentado ninguna observación al respecto, la Corte no otorga particulares gastos y costas en el presente caso"39.

Por su parte, en cuanto a la representación pro bono, como aspecto que reduce la condena en costas el Tribunal Continental ha señalado:

199. (...) En el ámbito internacional, conforme lo señalaron los representantes, tampoco se habría incurrido en erogaciones a título de asistencia jurídica, visto que aquellos actuaron pro bono. Sin embargo, la Corte también advierte que los representantes de las víctimas incurrieron en gastos para asistir a la audiencia pública del caso celebrada en la ciudad de Santiago,

39 Corte Interamericana de Derechos Humanos, Corte IDH, Caso Caesar vs. Trinidad y Tobago, Sentencia 11 de marzo 2005, Fondo, reparaciones y costas, Serie C 123, párrafo 135. Disponible en: http://www.corteidh.or.cr/docs/casos/articulos/seriec_123_esp.pdf 
Chile, así como gastos relativos al ejercicio de su representación legal, tales como la remisión de sus escritos, gastos de comunicación, entre otros, durante el proceso ante este Tribunal. Teniendo en cuenta lo anterior y ante la falta de comprobantes de estos gastos, la Corte determina, en equidad, que el Estado debe entregar la cantidad de US\$8.000,00 (ocho mil dólares de los Estados Unidos de América) por concepto de costas y gastos $^{40}$.

En esa misma dirección, esa instancia internacional también ha considerado lo siguiente:

283. La Corte, con base en lo dispuesto por sujurisprudencia, observa que, desde 2002, la familia de Néstor José Uzcátegui contó con el apoyo pro bono de COFAVIC [Comité de Familiares de las Victimas de los Sucesos de Febrero-Marzo de 1989] para los procesos legales internos y que los representantes no remitieron prueba alguna de los gastos incurridos por la familia Uzcátegui-Jiménez en los procesos legales internos. Sin embargo, infiriendo que la familia incurrió en varios gastos desde el inicio de dichos procesos, la Corte decide fijar, en equidad, la suma de US\$5.000,00 (cinco mil dólares de los Estados Unidos de América), la cual deberá ser entregada al señor Luis Enrique Uzcátegui ${ }^{41}$.

\section{GASTOS NO CUBIERTOS POR LAS COSTAS}

Como se verá a continuación, en el trámite ante la Corte Interamericana también es posible que el monto de costas sea reducido por la exclusión de ciertos desembolsos que - estima el Tribunal — no deben incluirse dentro de la definición expuesta líneas atrás.

En lo que hace a la improcedencia del resarcimiento de ciertos gastos, el Tribunal continental ha efectuado denegatorias como la siguiente:

40 Corte Interamericana de Derechos Humanos, Corte IDH, Caso Garibaldi vs. Brasil, Sentencia de 23 de septiembre de 2009, Excepciones preliminares, fondo, reparaciones y costas, Serie C 203, párrafo 199. Disponible en: http://www.corteidh.or.cr/docs/casos/articulos/seriec_203_esp. pdf

41 Corte Interamericana de Derechos Humanos, Corte IDH, Caso Uzcátegui y otros vs. Venezuela, Sentencia de 3 de septiembre de 2012, Fondo y Reparaciones, Serie C 249, párrafo 283. Disponible en: http://www.corteidh.or.cr/docs/casos/articulos/seriec_249_esp.pdf 
47. Luego de un examen detallado de los documentos relativos a esos gastos, la Corte observa que una parte importante de ellos corresponden a gastos de viaje y llamadas telefónicas fuera de Colombia, a publicaciones periodísticas y elaboración de afiches y pancartas realizados por el Sindicato de Educadores de Santander y la Comisión Andina de Juristas y no por la señora María Nodelia Parra-Rodríguez, por lo cual no pueden ser incluidos en los gastos reembolsables conforme al punto resolutivo número 6 de la sentencia de fondo dictada por esta Corte, la que solo reconoce los gastos relacionados con gestiones de los familiares de las víctimas ante las autoridades colombianas ${ }^{42}$.

\section{En sentido similar, la Corte también ha considerado:}

316. (...) Sin embargo, en sus alegatos finales escritos, los representantes actualizaron su solicitud en cuanto a las costas y gastos con aquellos incurridos para asistir a la audiencia pública convocada por el Tribunal en el presente caso, lo cual es totalmente procedente. Para ello, los representantes realizaron un detalle de los gastos incurridos y adjuntaron facturas y recibos como prueba de los mismos. El monto de estos gastos asciende a aproximadamente USD \$12,017.47.00 [sic]. Sin embargo, la Corte ha constatado que los comprobantes remitidos por los representantes corresponden a los gastos incurridos durante el traslado y la estadía en Costa Rica de 21 personas: cuatro personas correspondientes al equipo de asistencia legal de ADIVIMA [Asociación para el Desarrollo Integral de las Victimas de la Violencia en las Verapaces, Maya Achí], representantes en este caso, dos presuntas victimas declarantes, el perito Michael Paul Hermann-Mörth, el líder maya Juan de Dios García-Xajil y 13 personas más. Al respecto, al no comprobarse la estricta necesidad de la presencia de estas últimas trece personas en el Tribunal para el litigio del presente caso, el costo del traslado hasta Costa Rica de las mismas no se considerará como parte de los gastos incurridos por los representantes ${ }^{43}$.

42 Corte Interamericana de Derechos Humanos, Corte IDH, Caso Caballero-Delgado y Santana vs. Colombia, Sentencia de 29 de enero de 1997, Reparaciones y costas, Serie C 31, párrafo 47. Disponible en: http://www.corteidh.or.cr/docs/casos/articulos/seriec_31_esp.pdf

43 Corte Interamericana de Derechos Humanos, Corte IDH, Caso Masacres de Río Negro vs. Guatemala, Sentencia de 4 de septiembre de 2012, Excepción preliminar, fondo, reparaciones y costas, Serie C 250, párrafo 316. Disponible en: http://www.corteidh.or.cr/docs/casos/articulos/ seriec_250_esp.pdf 


\section{EXONERACIÓN TRIBUTARIA RESPECTO DE LAS COSTAS OTORGADAS EN EL SISTEMA INTERAMERICANO}

\section{Como último de los puntos a analizar en el presente trabajo, se ha estimado conveniente hacer una breve referencia al criterio relativo a la imposibilidad de gravar con cargas tributarias los montos otorgados por la Corte Interamericana en concepto de costas. En esta dirección, esa instancia judicial ha considerado:}

41. Dentro del contexto citado, el monto del pago ordenado en favor de los abogados del señor Suárez-Rosero fue considerado, en su oportunidad, como equitativo y razonable. La esencia misma del fallo de la Corte en lo atinente a este aspecto es que, como parte de la justa indemnización a que hace referencia el artículo 63.1 de la Convención, es tanto "equitativo" como "razonable" que los abogados de la víctima reciban dichas cantidades en forma íntegra y efectiva. Si el Estado dedujese algún porcentaje de estas cantidades por concepto de gravámenes, el monto recibido por los abogados no sería el mismo que aquel sobre el cual la Corte emitió pronunciamiento. Por lo tanto, en la hipótesis mencionada, no se estaría dando cumplimiento a lo ordenado en la sentencia sobre reparaciones. 42. La interpretación dada por la Corte sobre este aspecto es concordante con su jurisprudencia constante (ver, entre otros, Caso Loayza-Tamayo, Reparaciones (art. 63.1 Convención Americana sobre Derechos Humanos), Sentencia de 27 de noviembre de 1998. Serie C No.42, punto resolutivo noveno; y Caso Blake, Reparaciones (art. 63.1 Convención Americana sobre Derechos Humanos), Sentencia de 22 de enero de 1999. Serie C No. 48, punto resolutivo cuarto) y con la de la Corte Europea de Derechos Humanos, la cual, cuando ordena el pago de las costas, requiere al Estado que añada al pago los impuestos que podrían ser aplicables (ver, entre otros, Cour eur. D. H., arrêt Bulut c. Autriche du 22 février 1996, Recueil des arrêts et décisions 1996-II, punto resolutivo cuarto) o realiza el cálculo respectivo ella misma y ordena el pago del monto resultante (ver, entre otros, Cour eur. D.H., arrêt Young, James et Webster du 18 octobre 1982 (article 50), série A $n^{\circ} 55$, punto resolutivo segundo). 43. La Corte ha observado ya que tanto la Comisión como el señor Suárez-Rosero han propuesto algunos mecanismos para evitar que los abogados sean perjudicados por el pago de impuestos. La Corte considera que no es pertinente emitir pronunciamiento sobre dichos aspectos de la modalidad de cumplimiento. Ya la Corte ha indicado que del texto de la sentencia sobre reparaciones se desprende con claridad la obligación estatal de pagar los montos ordenados y de hacerlo en forma integral y que, en orden a cumplir con este objetivo, el Ecuador debe 
aplicar los mecanismos que resulten idóneos para asegurar el cumplimiento de esta obligación de la manera más expedita y eficiente, en las condiciones $y$ dentro del plazo ordenados por la Corte. 44. Por las razones anteriores, la Corte considera que el pago de las costas y los gastos ordenado en favor de los abogados del señor Suárez-Rosero no puede ser gravado con tributo alguno por el Estado ${ }^{44}$.

Más de una década después de la emisión del criterio recién expuesto, la Corte ha mantenido dicho criterio al establecer: "150. Las cantidades asignadas en la presente Sentencia como indemnización y como reintegro de costas y gastos deberán ser entregadas a las personas indicadas en forma íntegra conforme a lo establecido en este Fallo, sin reducciones derivadas de eventuales cargas fiscales" ${ }^{45}$.

44 Corte Interamericana de Derechos Humanos, Corte IDH, Caso Suárez-Rosero vs. Ecuador, Sentencia de 29 de mayo de 1999, Interpretación de la sentencia de reparaciones, Serie C 51, párrafos 42, 43, 44. Disponible en: http://www.corteidh.or.cr/docs/casos/articulos/seriec_51_esp. pdf. Corte Interamericana de Derechos Humanos, Corte IDH, Caso Loayza-Tamayo vs. Perú, Sentencia de 27 de noviembre de 1998, Reparaciones y costas, Serie C 42. Disponible en: http:// www.corteidh.or.cr/docs/casos/articulos/seriec_42_esp.pdf. Corte Interamericana de Derechos Humanos, Corte IDH, Caso Blake vs. Guatemala, Sentencia de 22 de enero de 1999, Reparaciones y costas, Serie C 48. Disponible en: http://www.corteidh.or.cr/docs/casos/articulos/ seriec_48_esp.pdf. Conseil de l'Europe, Cour Européenne des Droits de l'Homme, Arrêt Bulut contre Autriche, Requête 17358/90, 22 février 1996. Disponible en: http://hudoc.echr.coe.int/app/ conversion/pdf/?library=ECHR\&id=001-62530\&filename $=001-62530$.pdf\&TID=ihgdqbxnfi. Conseil de l'Europe, Cour Européenne des Droits de l'Homme, Arrêt Young, James et Webster, 18 octobre 1982 (article 50), série A 55. Disponible en: https://www.doctrine.fr/CEDH/HFJUD/ CHAMBER/1982/CEDH001-62163.

45 Corte Interamericana de Derechos Humanos, Corte IDH, Caso Vera-Vera y otra vs. Ecuador, Sentencia de 19 de mayo de 2011, Excepción preliminar, fondo, reparaciones y costas, Serie C 226, párrafo 150. Disponible en: http://www.corteidh.or.cr/docs/casos/articulos/seriec_226_esp. pdf 
CONCLUSIONES

Como primer hallazgo del presente estudio se debe señalar que en las convenciones que reglamentan la actividad de la Corte Interamericana no se han incorporado regulaciones sobre costas. No obstante ello, ese Tribunal continental ha estimado jurisprudencialmente que estas tienen sustento convencional al entender que son parte de las reparaciones. Por otra parte, si bien las costas se mencionan en el Reglamento, en los textos infraconvencionales tampoco se ha ofrecido ningún desarrollo sobre el particular.

En sus precedentes, el Tribunal ha precisado que las costas y las indemnizaciones por daños son conceptos distintos que forman parte de las reparaciones, comprendiendo las primeras los gastos generados tanto ante las autoridades de la jurisdicción interna, como ante el Sistema Interamericano.

La incorporación de las costas como parte de las reparaciones en los términos recién apuntados, genera conclusiones que deben ser objeto de atención. El reconocimiento de costas en el trámite internacional por gastos derivados de procesos internos que actualmente efectúa el Tribunal Interamericano, equivale a otorgar costas en un proceso en razón de gastos producidos en otro litigio - el interno - , pese a tratarse de procesos autónomos como reiteradamente lo ha señalado la Corte al referirse a la teoría de la cuarta instancia. En segundo término, conceptualizar las costas como un tipo de reparación ha implicado que estas no se hayan otorgado en favor de los Estados que han triunfado en los litigios en esa sede supranacional.

Del estudio de casos ante el Tribunal Continental, también ha resultado evidente que las regulaciones nacionales sobre ese particular no limitan la competencia de la Corte.

En lo que hace al tema de la procedencia del otorgamiento de las costas, ello dependerá en primer término del tipo de representación con que las presuntas víctimas han litigado ante el Tribunal supraestatal. No será procedente la condena en este rubro - costas - en el proceso supraestatal, cuando las presun- 
tas víctimas estén representadas por la Comisión Interamericana de Derechos Humanos, o por instituciones públicas nacionales, sean Defensorías o Procuraciones Públicas, o instituciones Defensoras de Derechos Humanos tipo Defensorías del Pueblo u Ombudsman. Por otra parte, sí será procedente el pago de costas cuando el asesoramiento haya estado a cargo de profesionales independientes u organizaciones no gubernamentales.

Precisado lo anterior, se debe indicar que el Tribunal ha establecido algunos parámetros para cuantificar las costas a otorgar, entre los que están los siguientes: el aporte de elementos probatorios para sustentar los hechos expuestos por las partes, el consejo legal que se brinde, la diligencia en el cumplimiento de las distintas gestiones procedimentales ante el Tribunal y el grado de conocimiento de la jurisprudencia internacional. Finalmente, se debe precisar que la Corte ha dado cabida a los contratos de cuotalitis en esta materia.

En lo que respecta al tema de la exoneración - total o parcial - de las costas en los procesos ante la Corte Interamericana de Derechos Humanos, al no haber una reglamentación de tales supuestos, estos han sido desarrollados por la jurisprudencia, sin que se establezcan parámetros generales sobre este particular.

Finalmente, se debe destacar como conclusión general que si bien la falta de regulación convencional y reglamentaria — más allá de su simple enunciación en las citadas normas secundarias - ha permitido que el Tribunal Continental no esté condicionado por regulaciones previamente establecidas, ajustando sus decisiones a cada litigio, es evidente que es justamente este el punto débil del instituto bajo análisis, pues su tratamiento en la mayor parte de los casos ha sido casuístico, sin que se establezcan parámetros generales que deban ser atendidos tanto por las partes y/o por la Corte - con independencia de su integración-, lo que afecta la seguridad jurídica en lo que hace a este tema. 


\section{BIBLIOGRAFÍA}

\section{Tratados internacionales}

Organización de Estados Americanos, OEA, Convención Americana sobre Derechos Humanos, Pacto de San José, San José, Costa Rica, 7 al 22 de noviembre de 1969. Disponible en: https://www.oas.org/dil/esp/tratados_B-32_Convencion_Americana _sobre_Derechos_Humanos.htm

Reglamento de la Corte Interamericana de Derechos Humanos, aprobado por la Corte en su XLIX Período Ordinario de Sesiones, celebrado del 16 al 25 de noviembre de 2001 y reformado parcialmente por la Corte en su LXXXII Período Ordinario de Sesiones, celebrado del 19 al 31 de enero de 2009. Disponible en: https://www. cidh.oas.org/basicos/Basicos12.htm. Reglamentos anteriores disponibles en: http:// www.corteidh.or.cr/index.php/es/acerca-de/reglamento/reglamentos-anteriores

\section{Jurisprudencia de la Corte Interamericana de Derechos Humanos, Corte IDH}

Corte Interamericana de Derechos Humanos, Corte IDH, Caso Abrill-Alosilla y otros vs. Perú, Sentencia de 4 de marzo de 2011, Fondo, reparaciones y costas, Serie C 223. Disponible en: http://www.corteidh.or.cr/docs/casos/articulos/seriec_223_esp.pdf

Corte Interamericana de Derechos Humanos, Corte IDH, Caso Alfonso Martín del Campo-Dodd vs. México, Sentencia de 3 de septiembre de 2004, Excepciones preliminares, Serie C 113. Disponible en: http://www.corteidh.or.cr/docs/casos/ articulos/seriec_113_esp.pdf

Corte Interamericana de Derechos Humanos, Corte IDH, Caso Aloeboetoe y otros vs. Surinam, Sentencia de 10 de septiembre de 1993, Reparaciones y costas, Serie C 15. Disponible en: http://www.cidh.oas.org/Indigenas/seriec_15_esp.pdf

Corte Interamericana de Derechos Humanos, Corte IDH, Caso Artavia-Murillo y otros (Fecundación in vitro) vs. Costa Rica, Sentencia de 28 noviembre de 2012, Excepciones preliminares, fondo, reparaciones y costas, Serie C 257. Disponible en: http://www.corteidh.or.cr/docs/casos/articulos/seriec_257_esp.pdf

Corte Interamericana de Derechos Humanos, Corte IDH, Caso Bayarri vs. Argentina, Sentencia de 30 de octubre de 2008, Excepción preliminar, fondo, reparaciones y costas, Serie C 187. Disponible en: http://www.corteidh.or.cr/docs/casos/articulos/ seriec_187_esp.pdf

Corte Interamericana de Derechos Humanos, Corte IDH, Caso Blake vs. Guatemala, Sentencia de 22 de enero de 1999, Reparaciones y costas, Serie C 48. Disponible en: http://www.corteidh.or.cr/docs/casos/articulos/seriec_48_esp.pdf

Corte Interamericana de Derechos Humanos, Corte IDH, Caso Brewer-Carias vs. Venezuela, Sentencia de 26 de mayo de 2014, Excepciones preliminares, Serie C 278. Disponible en: http://www.corteidh.or.cr/docs/casos/articulos/seriec_278_esp.pdf

Corte Interamericana de Derechos Humanos, Corte IDH, Caso Bueno-Alves vs. Argen- 
tina, Sentencia de 11 de mayo de 2007, Fondo, reparaciones y costas, Serie C 164. Disponible en: http://www.corteidh.or.cr/docs/casos/articulos/seriec_164_esp.pdf

Corte Interamericana de Derechos Humanos, Corte IDH, Caso Caballero-Delgado y Santana vs. Colombia, Sentencia de 29 de enero de 1997, Reparaciones y costas, Serie C 31. Disponible en: http://www.corteidh.or.cr/docs/casos/articulos/ seriec_31_esp.pdf

Corte Interamericana de Derechos Humanos, Corte IDH, Caso Caesar vs. Trinidady Tobago, Sentencia 11 de marzo 2005, Fondo, reparaciones y costas, Serie C 123. Disponible en: http://www.corteidh.or.cr/docs/casos/articulos/seriec_123_esp.pdf

Corte Interamericana de Derechos Humanos, Corte IDH, Caso Castillo-González y otros vs. Venezuela, Sentencia de 27 de noviembre de 2012, Fondo, Serie C 256. Disponible en: http://www.corteidh.or.cr/docs/casos/articulos/seriec_256_esp.pdf

Corte Interamericana de Derechos Humanos, Corte IDH, Caso Castillo-Petruzzi y otros vs. Perú, Sentencia de 4 de septiembre de 1998, Excepciones preliminares, Serie C 41. Disponible en: http://www.corteidh.or.cr/docs/casos/articulos/seriec_41_esp.pdf

Corte Interamericana de Derechos Humanos, Corte IDH, Caso Chaparro-Álvarez y Lapo-Íñiguez vs. Ecuador, Sentencia de 21 de noviembre de 2007, Excepciones preliminares, fondo, reparaciones y costas, Serie C 170. Disponible en: http://www. corteidh.or.cr/docs/casos/articulos/seriec_170_esp.pdf

Corte Interamericana de Derechos Humanos, Corte IDH, Caso Chitay-Nech y otros vs. Guatemala, Sentencia de 25 de mayo de 2010, Excepciones preliminares, fondo, reparaciones y costas, Serie C 212. Disponible en: http://www.corteidh.or.cr/docs/ casos/articulos/seriec_212_esp.pdf

Corte Interamericana de Derechos Humanos, Corte IDH, Caso Comunidad Indigena Xákmok Kásek vs. Paraguay, Sentencia de 24 de agosto de 2010, Fondo, reparaciones y costas, Serie C 214. Disponible en: http://www.corteidh.or.cr/docs/casos/ articulos/seriec_214_esp.pdf

Corte Interamericana de Derechos Humanos, Corte IDH, Caso de la "Panel Blanca" (Paniagua-Morales y otros) vs. Guatemala, Sentencia de 25 de mayo de 2001, Reparaciones y Costas, Serie C 76. Disponible en: http://www.corteidh.or.cr/docs/ casos/articulos/Seriec_76_esp.pdf

Corte Interamericana de Derechos Humanos, Corte IDH, Caso de los Pueblos Indigenas Kuna de Madungandi y Emberá de Bayano y sus miembros vs. Panamá, Sentencia de 14 de octubre de 2014, Excepciones preliminares, fondo, reparaciones y costas, Serie C 284. Disponible en: http://www.corteidh.or.cr/docs/casos/articulos/ seriec_284_esp.pdf

Corte Interamericana de Derechos Humanos, Corte IDH, Caso Fairén-Garbi y SolísCorrales vs. Honduras, Sentencia de 15 de marzo de 1989, Fondo, Serie C 6. Disponible en: http://www.corteidh.or.cr/docs/casos/articulos/seriec_06_esp.pdf

Corte Interamericana de Derechos Humanos, Corte IDH, Caso Fermín Ramírez vs. Guatemala, Sentencia de 20 de junio de 2005, Fondo, reparaciones y costas, Serie C 126. Disponible en: http://www.corteidh.or.cr/docs/casos/articulos/seriec_126_esp.pdf

Corte Interamericana de Derechos Humanos, Corte IDH, Caso Fleury y otros vs. Haití, Sentencia de 23 de noviembre de 2011, Fondo y reparaciones, Serie C 236. Disponible 
en: http://corteidh.or.cr/docs/casos/articulos/seriec_236_esp.pdf

Corte Interamericana de Derechos Humanos, Corte IDH, Caso Gangaram-Panday vs. Surinam, Sentencia de 21 de enero de 1994, Fondo, reparaciones y costas, Serie C 16. Disponible en: http://www.corteidh.or.cr/docs/casos/articulos/seriec_16_esp.pdf

Corte Interamericana de Derechos Humanos, Corte IDH, Caso García-Lucero y otras vs. Chile, Sentencia de 28 de agosto de 2013, Excepción preliminar, fondo y reparaciones, Serie C 267. Disponible en: http://www.corteidh.or.cr/docs/casos/ articulos/seriec_267_esp.pdf

Corte Interamericana de Derechos Humanos, Corte IDH, Caso Garibaldi vs. Brasil, Sentencia de 23 de septiembre de 2009, Excepciones preliminares, fondo, reparaciones y costas, Serie C 203. Disponible en: http://www.corteidh.or.cr/docs/casos/ articulos/seriec_203_esp.pdf

Corte Interamericana de Derechos Humanos, Corte IDH, Caso Garrido y Baigorria vs. Argentina, Sentencia de 27 de agosto de 1998, Reparaciones y costas, Serie C 39. Disponible en: http://www.corteidh.or.cr/docs/casos/articulos/seriec_39_esp.pdf

Corte Interamericana de Derechos Humanos, Corte IDH, Caso Grande vs. Argentina, Sentencia de 31 de agosto de 2011, Excepciones preliminares y fondo, Serie C 231. Disponible en: http://www.corteidh.or.cr/docs/casos/articulos/seriec_231_esp.pdf

Corte Interamericana de Derechos Humanos, Corte IDH, Caso Granier y otros (Radio Caracas Televisión) vs. Venezuela, Sentencia de 22 de junio de 2015, Excepciones preliminares, fondo, reparaciones y costas, Serie C 293. Disponible en: http://www. corteidh.or.cr/docs/casos/articulos/seriec_293_esp.pdf

Corte Interamericana de Derechos Humanos, Corte IDH, Caso Ibsen-Cárdenas e Ibsen-Peña vs. Bolivia, Sentencia de 1 de septiembre de 2010, Fondo, reparaciones y costas, Serie C No. 217. Disponible en: http://www.corteidh.or.cr/docs/casos/ articulos/seriec_217_espl.pdf

Corte Interamericana de Derechos Humanos, Corte IDH, Caso Kimel vs. Argentina, Sentencia de 2 de mayo de 2008, Fondo, reparaciones y costas, Serie C 177. Disponible en: http://www.corteidh.or.cr/docs/casos/articulos/seriec_177_esp.pdf

Corte Interamericana de Derechos Humanos, Corte IDH, Caso Loayza-Tamayo vs. Perú, Sentencia de 27 de noviembre de 1998, Reparaciones y costas, Serie C 42. Disponible en: http://www.corteidh.or.cr/docs/casos/articulos/seriec_42_esp.pdf

Corte Interamericana de Derechos Humanos, Corte IDH, Caso Manuel Cepeda-Vargas vs. Colombia, Sentencia de 26 de mayo de 2010, Excepciones preliminares, fondo, reparaciones y costas, Serie C 213. Disponible en: http://www.corteidh.or.cr/docs/ casos/articulos/seriec_213_esp.pdf

Corte Interamericana de Derechos Humanos, Corte IDH, Caso Masacre de Santo Domingo vs. Colombia, Sentencia de 30 de noviembre de 2012, Excepciones preliminares, fondo y reparaciones, Serie C 259. Disponible en: http://www.corteidh. or.cr/docs/casos/articulos/seriec_259_esp.pdf

Corte Interamericana de Derechos Humanos, Corte IDH, Caso Masacres de Río Negro vs. Guatemala, Sentencia de 4 de septiembre de 2012, Excepción preliminar, fondo, reparaciones y costas, Serie C 250. Disponible en: http://www.corteidh.or.cr/docs/ casos/articulos/seriec_250_esp.pdf 
Corte Interamericana de Derechos Humanos, Corte IDH, Caso Mémoli vs. Argentina, Sentencia de 22 de agosto de 2013, Excepciones preliminares, fondo, reparaciones y costas, Serie C 265. Disponible en: http://www.corteidh.or.cr/docs/casos/articulos/ seriec_265_esp.pdf

Corte Interamericana de Derechos Humanos, Corte IDH, Caso Mendoza y otros vs. Argentina, Sentencia de 14 de mayo de 2013, Excepciones preliminares, fondo y reparaciones, Serie C 260. Disponible en: http://www.corteidh.or.cr/docs/casos/ articulos/resumen_260_esp.pdf

Corte Interamericana de Derechos Humanos, Corte IDH, Caso Nogueira de Carvalho y otro vs. Brasil, Sentencia de 28 de noviembre de 2006, Excepciones preliminares y fondo, Serie C 161. Disponible en: http://www.corteidh.or.cr/docs/casos/articulos/ seriec_161_esp1.pdf

Corte Interamericana de Derechos Humanos, Corte IDH, Caso Palma-Mendoza y otros vs. Ecuador, Sentencia de 3 de septiembre de 2012, Excepción preliminar y fondo, Serie C 247. Disponible en: http://www.corteidh.or.cr/docs/casos/articulos/ seriec_247_esp.pdf

Corte Interamericana de Derechos Humanos, Corte IDH, Caso Ricardo Canese vs. Paraguay, Sentencia de 31 de agosto de 2004, Fondo, reparaciones y costas, Serie C 111. Disponible en: http://www.corteidh.or.cr/docs/casos/articulos/seriec_111_esp.pdf

Corte Interamericana de Derechos Humanos, Corte IDH, Caso Suárez-Rosero vs. Ecuador, Sentencia de 29 de mayo de 1999, Interpretación de la sentencia de reparaciones, Serie C 51. Disponible en: http://www.corteidh.or.cr/docs/casos/articulos/ seriec_51_esp.pdf

Corte Interamericana de Derechos Humanos, Corte IDH, Caso Ticona-Estrada y otros vs. Bolivia, Sentencia de 27 de noviembre de 2008, Fondo, reparaciones y costas, Serie C 191. Disponible en: http://www.corteidh.or.cr/docs/casos/expedientes/ seriec_191_esp.pdf

Corte Interamericana de Derechos Humanos, Corte IDH, Caso Uzcátegui y otros vs. Venezuela, Sentencia de 3 de septiembre de 2012, Fondo y Reparaciones, Serie C 249. Disponible en: http://www.corteidh.or.cr/docs/casos/articulos/seriec_249_esp.pdf

Corte Interamericana de Derechos Humanos, Corte IDH, Caso Vélez-Loor vs. Panamá, Sentencia de 23 de noviembre de 2010, Excepciones preliminares, fondo, reparaciones y costas, Serie C 218. Disponible en: http://www.corteidh.or.cr/docs/casos/ articulos/seriec_218_esp2.pdf

Corte Interamericana de Derechos Humanos, Corte IDH, Caso Veliz-Franco y otros vs. Guatemala, Sentencia de 19 de mayo de 2014, Excepciones preliminares, fondo, reparaciones y costas, Serie C 277. Disponible en: http://www.corteidh.or.cr/docs/ casos/articulos/seriec_277_esp.pdf

Corte Interamericana de Derechos Humanos, Corte IDH, Caso Vera-Vera y otra vs. Ecuador, Sentencia de 19 de mayo de 2011, Excepción preliminar, fondo, reparaciones y costas, Serie C 226. Disponible en: http://www.corteidh.or.cr/docs/casos/ articulos/seriec_226_esp.pdf

Corte Interamericana de Derechos Humanos, Corte IDH, Opinión Consultiva OC16/99 de 1 de octubre de 1999, solicitada por los Estados Unidos Mexicanos, Serie A 16, El Derecho a la Información sobre la Asistencia Consular en el Marco de 
las Garantías del Debido Proceso Legal. Disponible en: http://www.corteidh.or.cr/ docs/opiniones/seriea_16_esp.pdf

\section{Jurisprudencia internacional}

Conseil de l'Europe, Cour Européenne des Droits de l'Homme, Arrêt Bulut contre Autriche, Requête 17358/90, 22 février 1996. Disponible en: http://hudoc.echr. coe.int/app/conversion/pdf/?library=ECHR\&id=001-62530\&filename=001-62530. pdf\&TID=ihgdqbxnfi

Conseil de l'Europe, Cour Européenne des Droits de l'Homme, Arrêt Young, James et Webster, 18 octobre 1982 (article 50), série A 55. Disponible en: https://www. doctrine.fr/CEDH/HFJUD/CHAMBER/1982/CEDH001-62163

Paraguay, Corte Suprema de Justicia, Sala Penal, Expediente: Ricardo Nicolás CaneseKrivoshein sobre difamación e injuria, Acuerdo y sentencia 804, 27 de abril de 2004. Disponible en: http://www.csj.gov.py/jurisprudencia/default.aspx?AspxAut oDetectCookieSupport $=1$ 
